JURNAL SEHAT MASADA VOLUME XIV NOMOR 1 Januari 2020 ISSN : 1979-2344

\title{
FAKTOR-FAKTOR PESERTA JAMINAN KESEHATAN NASIONAL (JKN) PENERIMA BANTUAN IURAN (PBI) YANG BEHUBUNGAN DENGAN PEMANFAATAN PELAYANAN KESEHATAN DI WILAYAH KERJA PUSKESMAS MANDALA MEKAR KOTA BANDUNG
}

\author{
Gugum Pamungkas ${ }^{1)}$, Neli Naelul Inayah ${ }^{2)}$ \\ ${ }^{1,2)}$ Program Studi Sarjana Kesehatan Masyarakat STIKes Dharma Husada Bandung \\ gugumpamungkas@gmail.com \\ 2) nelinaelul18@gmail.com
}

\begin{abstract}
Health insurance is a guarantee in the form of health protection so that participants get the benefits of health care and protection in meeting basic health needs. National Health Insurance membership consists of Beneficiary Contribution (PBI) and not PBI. Mandala Mekar Health Center is the health center with the lowest number of visits, 866 (30,6\%) out of 2,827 (69,4\%) National Health Insurance participants, with PBI participants totaling 1867 (66\%) participants. The purpose of this study was to determine the factors of PBI National Health Insurance Participants (JKN) related to the utilization of health services in the working area of the Mandala Mekar Community Health Center in Bandung. The research method was quantitative, cross sectional design with a population of 1867 (66\%) PBI participants. Sampling with Accidental sampling technique as many as 72 people. Data analysis using Chi Square Test. The results of the study, which utilized the health services of 28 people $(38,9 \%)$ and who did not utilize 44 people $(61,1 \%)$. There is a relationship between age, utilization of health services with $(p=0.007)$ and attitude $(p=0.011)$. There is no relationship of belief, location of facilities, and needs with the utilization of health services.
\end{abstract}

Keywords : National Health Insurance Utilization, Recipients of Participation and Health Services

\begin{abstract}
ABSTRAK
Latar Belakang: Jaminan kesehatan merupakan jaminan berupa perlindungan kesehatan agar peserta memperoleh manfaat pemeliharaan kesehatan dan perlindungan dalam memenuhi kebutuhan dasar kesehatan. Kepesertaan JKN terdiri dari PBI dan Bukan PBI. Puskesmas Mandala Mekar adalah puskesmas dengan jumlah kunjungan terendah yaitu 866 atau $(30,6 \%)$ dari 2.827 atau $(69,4 \%)$ peserta JKN, dengan peserta PBI sebanyak 1867 atau (66\%) peserta. Tujuan: untuk Mengetahui FaktorFaktor Peserta Jaminan Kesehatan Nasional (JKN) PBI yang Berhubungan dengan Pemanfaatan Pelayanan Kesehatan di wilayah kerja Puskesmas Mandala Mekar kota Bandung. Metode: Metode penelitian kuantitataif, dengan desain Cros sectional dengan populasi sebanyak 1867 atau (66\%) peserta PBI. Pengambilan sampel dengan tehnik Accidental sampling sebanyak 72 orang.

Hasil: Analisis data menggunkan Uji Chi Square. Hasil penelitian, yang memanfaatkan pelayanan kesehatan 28 orang atau $(38,9 \%)$ dan yang tidak memanfaatkan 44 orang atau $(61,1 \%)$. Simpulan: Ada hubungan antara umur, dengan pemanfaatan pelayanan kesehatan dengan $(\mathrm{p}=0,007)$ dan sikap $(\mathrm{p}=0,011)$. Tidak ada hubunga keyakinan, lokasi sarana, dan kebutuhan dengan Pemanfaatan pelayanan kesehatan
\end{abstract}

Kata Kunci : Pemanfaatan JKN , Kepesertaan PBI dan pemanfaatan Pelayanan Kesehatan 


\section{PENDAHULUAN}

Kesehatan adalah hak fundamental setiap warga $^{1}$. Oleh karenanya setiap individu, keluarga dan masyarakat berhak memperoleh perlindungan terhadap kesehatannya. Dalam Undang-Undang ${ }^{1}$ menyatakan Kesehatan adalah "keadaan sehat, baik secara fisik, mental, spritual maupun sosial yang memungkinkan setiap orang untuk hidup produktif secara sosial dan ekonomis. Oleh karena itu perlu adanya upaya peningktan pelayanan kesehatan. Upaya pemerintah dalam meningkatkan pelayanan kesehatan adalah dengan mengeluarkan UndangUndang $^{2}$ tentang sistem Jaminan Sosial Nasional (SJSN). Salah satu bentuk program dari sistem jaminan SJSN yaitu sistem Jaminan Kesehatan Nasional (JKN).

Jaminan kesehatan merupakan jaminan berupa perlindungan kesehatan agar peserta memperoleh manfaat pemeliharaan kesehatan dan perlindungan dalam memenuhi kebutuhan dasar kesehatan yang diberikan kepada setiap orang yang telah membayar iuran jaminan kesehatan atau iuran jaminan kesehatannya di bayar oleh Pemerintah Pusat atau pemerintah. ${ }^{3}$

Jaminan Kesehatan terdiri dari peserta Penerima Bantuan Iuran (PBI) jaminan Kesehatan dan Bukan PBI jaminan kesehatan. Peserta PBI adalah peserta Penerima Bantuan Iuran Jaminan Kesehatan meliputi orang yang tergolong fakir miskin dan orang tidak mampu, sedangkan peserta bukan PBI adalah peserta yang tidak tergolong fakir miskin yang terdiri dari Pekerja Penerima Upah (PPU), Pekerja Bukan Penerima Upah (PBPU), dan Penerima Upah (PU). Sistem JKN diselenggarakan oleh Badan Penyelenggara Jaminan Sosial (BPJS) Kesehatan.

Berdasarkan data Kementrian Kesehatan, cakupan kepesertaan Jaminana Kesehatan Nasional tahun 2018 jumlah kepesertaan JKN mencapai 99\%, yang terdiri dari kepesertaan bukan PBI sebanyak 41\%, PBI APBD sebanyak 14\% dan PBI APBN sebanyak 44\% peserta.

Di Provinsi Jawa Barat sendiri, Capaian kepesertaan pengguna JKN per 4 maret 2019 berjumlah 37.512 .702 atau $(83,57 \%)$ peserta dari jumlah penduduk sebanyak 44.886.479 jiwa.

Berdasarakan laporan Pengelolaan dan laporan Keuangan Program Jaminan Sosial Kesehatan, dari beberapa fasilitas kesehatan (faskes) yang ada, jumlah kunjungan kepesertaan JKN, yang berkunjung atau memanfaatkan fasilitas kesehatan dari tahun 2018 pada FKTP yang terdiri dari Puskesmas, Dokter peraktek perorangan/klinik Pratama sebanyak 147,4 juta kunjungan.

Berdasarkan teori Anderson dalam Notoatmodjo ${ }^{5}$ menyatakan bahwa keputusan seseorang dalam menggunakan atau memanfaatkan sarana pelayanan tergantung pada Karakteristik Predisposisi (Predisposing 
JURNAL SEHAT MASADA VOLUME XIV NOMOR 1 Januari 2020 ISSN : 1979-2344

Characteristic), Karakteristik Pendukung

(Enabling Characteristic) dan Karakteristik

Kebutuhan (Need Characteristik).

Hasil studi pendahuluan yang dilakukan di Dinas Kesehatan Kota Bandung, terdapat 80 puskesmas,. Dari 80 puskesmas yang terdaftar, terdapat puskesmas dengan jumlah kunjungan atau pemanfaatan puskesmas terendah, yaitu puskesmas Mandala Mekar, dengan jumlah kunjungan peserta JKN yang berobat sebanyak 866 atau $(30,6 \%)$ dari 2.827 atau $(69,4 \%)$ jumlah peserta JKN yang terdaftar di Puskesmas Mandala Mekar, yang terdiri dari peserta PBI sebanyak 1867 atau (66\%) peserta dan peserta bukan PBI sebanyak 883 atau (31\%) peserta.

Berdasarkan Uraian diatas, maka peneliti tertarik untuk melakukan penelitian dengan judul "Faktor-Faktor Peserta Jaminan Kesehatan Nasional (JKN) Penerima Bantuan Iuran (PBI) yang Berhubungan dengan Pemanfaatan Pelayanan Kesehatan di Wilayah Kerja Puskesmas Mandala Mekar Kota Bandung ".

\section{METODE PENELITIAN}

Penelitian ini adalah penelitian Deskriptif Kuantitatif. Pengambilan Sampel dengan Accidental sampling. Jumlah sample sebanyak 72 responden. Terdapat 5 variabel, yaitu : Umur, sikap, lokasi sarana, keyakinan dan kebutuhan. Metode pengumpulan data yang digunakan adalah dengan kuesioner. Pada penelitian ini data-data yang telah dikumpulkan dianalisis dengan analisis univariat dan bivariat.

\section{HASIL DAN PEMBAHASAN}

\section{Analisis Univariat}

a. Distribusi Frekuensi Variabel Independen

Tabel 1 Umur Peserta Jaminan Kesehatan Nasional (JKN) PBI di Puskesmas Mandala Mekar Kota Bandung

\begin{tabular}{llll}
\hline No & Umur & f & \% \\
\hline 1 & 15-50 tahun & 46 & 63,9 \\
2 & $>50$ tahun & 26 & 36,1 \\
\hline & Jumlah & $\mathbf{7 2}$ & $\mathbf{1 0 0}$ \\
\hline
\end{tabular}

Berdasarkan hasil uji Statistik pada tabel 1, umur Peserta Jaminan Kesehatan Nasional (JKN) PBI yang memanfaatkan Pelayanan kesehatan di Wilayah Kerja puskesmas Mandala Mekar Kota Bandung lebih dari setengahnya usia 15-50 tahun, yaitu sebanyak 46 orang $(63,9 \%)$ dan hampir setenganya peserta dengan Usia $>50$ tahun sebanyak 26 orang $(36,1 \%)$.

Tabel 2 Sikap Peserta Jaminan Kesehatan Nasional (JKN) PBI di Puskesmas Mandala Mekar Kota Bandung

\begin{tabular}{cccc}
\hline No & Sikap & f & \% \\
\hline 1 & Sikap Positif & 41 & 56.9 \\
2 & Sikap Negatif & 31 & 43.1 \\
\hline & Jumlah & $\mathbf{7 2}$ & $\mathbf{1 0 0}$ \\
\hline
\end{tabular}


Berdasarkan hasil uji statistik, pada tabel 2 diketahui bahwa sikap Peserta Jaminan Kesehatan Nasional (JKN) PBI yang memanfaatkan Pelayanan kesehatan di wilayah kerja puskesmas Mandala Mekar Kota Bandung lebih dari setengahnya menunjukan sikap yang positif yaitu 41 orang $(56,9 \%)$ dan hampir setengahnya menunjukan sikap negatif yaitu sebanyak 31 orang $(43,1 \%)$.

Tabel 3 Keyakinan Peserta Jaminan Kesehatan Nasional (JKN) PBI di Puskesmas Mandala Mekar Kota Bandung

\begin{tabular}{|c|c|c|c|}
\hline No & Keyakinan & f & $\%$ \\
\hline 1 & $\begin{array}{l}\text { Tingkat } \\
\text { Keyakinan } \\
\text { Tinggi }\end{array}$ & 61 & 84,7 \\
\hline 2 & $\begin{array}{l}\text { Tingkat } \\
\text { Keyakinan } \\
\text { Rendah }\end{array}$ & 11 & 15,3 \\
\hline & Jumlah & 72 & 100 \\
\hline
\end{tabular}

Berdasarkan tabel 3, diketahui bahwa keyakinan Peserta Jaminan Kesehatan Nasional (JKN) PBI yang memanfaatkan Pelayanan di wilayah kerja puskesmas Mandala Mekar Kota Bandung Hampir seluruhnya memiliki tingkat keyakinan tinggi yaitu sebanyak 61 orang $(84,7 \%)$ dan sebagian kecil memiliki tingkat keyakinan rendah sebanyak 11 orang $(15,3 \%)$.
Tabel 4 Lokasi Sarana bagi Peserta Jaminan Kesehatan Nasional (JKN) PBI di Puskesmas Mandala Mekar Kota Bandung

\begin{tabular}{llll}
\hline No & $\begin{array}{l}\text { Lokasi } \\
\text { Sarana }\end{array}$ & f & \% \\
\hline 1 & Terjangkau & 59 & 81,9 \\
2 & $\begin{array}{l}\text { Tidak } \\
\text { Terjangkau }\end{array}$ & 13 & 81,1 \\
& Jumlah & $\mathbf{7 2}$ & $\mathbf{1 0 0}$ \\
\hline
\end{tabular}

Berdasarkan tabel 4, lokasi sarana bagi Peserta Jaminan Kesehatan Nasional (JKN) PBI di wilayah kerja puskesmas Mandala Mekar Kota Bandung sebagian besar terjangkau yaitu sebanyak 59 orang $(81,9 \%)$ dan sebagian kecil tidak terjangkau yaitu, 13 orang $(18,1 \%)$.

Tabel 5 Kebutuhan yang Dirasakan Peserta Jaminan Kesehatan Nasional (JKN) PBI di Puskesmas Mandala Mekar Kota Bandung

\begin{tabular}{cccc}
\hline No & $\begin{array}{c}\text { Kebutuhan yang } \\
\text { dirasakan }\end{array}$ & f & \% \\
\hline 1 & Ya, Butuh & 57 & 79,2 \\
2 & Tidak Butuh & 15 & 20,8 \\
\hline & Jumlah & $\mathbf{7 2}$ & $\mathbf{1 0 0}$ \\
\hline
\end{tabular}

Berdasarkan tabel 5, kebutuhan yang dirasakan Peserta Jaminan Kesehatan Nasional (JKN) PBI terhadap pemanfaatan pelayanan kesehatan di Wilayah Kerja puskesmas Mandala Mekar Kota Bandung lebih dari setengahnya merasa butuh yaitu sebanyak 57 orang $(79,2 \%)$ dan hampir 
JURNAL SEHAT MASADA VOLUME XIV NOMOR 1 Januari 2020 ISSN : 1979-2344

setengahnya merasa tidak butuh sebanyak 15 orang $(20,8 \%)$.

\section{b. Distribusi Frekuensi Variabel Dependen}

Tabel 6 Pemanfaatan Jaminan Kesehatan Nasional (JKN) PBI di

Puskesmas Mandala Mekar

\begin{tabular}{cccc}
\hline No & Pemanfaatan & f & \% \\
\hline 1 & Memanfaatkan & 28 & 38.9 \\
\hline 2 & Tidak Memanfaatkan & 44 & 61.1 \\
\hline & Jumlah & $\mathbf{7 2}$ & $\mathbf{1 0 0}$ \\
\hline
\end{tabular}

Berdasarkan tabel 6, lebih dari setengahnya peserta JKN PBI tidak memanfaatkan yaitu sebanyak 44 orang $(61,1 \%)$ dan hampir setengahnya memanfaatkan sebanyak 28 orang $(38,9 \%)$.

\section{Analisis Bivariat}

a. Hubungan Faktor Umur Peserta Jaminan Kesehatan Nasional (JKN) PBI dengan Pemanfaatan Pelayanan Kesehatan di Wilayah Kerja Puskesmas Mandala Mekar Kota Bandung

Tabel 7 Hubungan Faktor Umur Peserta Jaminan Kesehatan Nasional (JKN) PBI dengan Pemanfaatan Pelayanan Kesehatan di Wilayah Kerja Puskesmas Mandala Mekar Kota Bandung

\begin{tabular}{lccccccc}
\hline \multirow{2}{*}{ Umur } & \multicolumn{6}{c}{ Pemanfaatan } & \\
\cline { 2 - 6 } & $\begin{array}{c}\text { Ya } \\
\text { Memanf } \\
\text { aatkan }\end{array}$ & $\begin{array}{c}\text { Tidak } \\
\text { Memanfa } \\
\text { atkan }\end{array}$ & Total & & \\
\cline { 2 - 6 } & $\mathbf{N}$ & $\mathbf{\%}$ & $\mathbf{N}$ & $\mathbf{\%}$ & $\mathbf{N}$ & $\mathbf{\%}$ & \\
\hline $\begin{array}{l}15-50 \\
\text { tahun } \\
>50\end{array}$ & 12 & 26,1 & 34 & 73,9 & 46 & 100 & 0,007 \\
tahun & 16 & 61,5 & 10 & 38,5 & 26 & 100 & \\
\hline Total & $\mathbf{2 8}$ & $\mathbf{3 8 . 9}$ & $\mathbf{4 4}$ & $\mathbf{6 1 , 1}$ & $\mathbf{7 2}$ & $\mathbf{1 0 0}$ & \\
\hline
\end{tabular}

Berdasarkan tabel 7, kelompok umur usia 1550 tahun yang memanfaatkan pelayanan kesehatan sebanyak 12 orang atau $(26,1 \%)$, dan yang tidak memanfaatkan sebanyak 34 orang atau (73,9\%). Sedangkan usia $>50$ tahun yang memanfaatkan pelayanan kesehatan sebanyak 16 orang atau $(61,5 \%)$ dan yang tidak memanfaatkan sebanyak 10 orang atau $(38,5 \%)$.

b. Hubungan Faktor Sikap Peserta Jaminan Kesehatan Nasional (JKN) PBI dengan Pemanfaatan Pelayanan Kesehatan di Wilayah Kerja Puskesmas Mandala Mekar Kota Bandung.

Tabel 8 Hubungan Faktor Sikap Peserta Jaminan Kesehatan Nasional (JKN) PBI dengan Pemanfaatan Pelayanan Kesehatan di Wilayah Kerja Puskesmas Mandala Mekar Kota Bandung.

\begin{tabular}{|c|c|c|c|c|c|c|c|}
\hline \multirow{3}{*}{ Sikap } & \multicolumn{6}{|c|}{ Pemanfaatan } & \multirow{3}{*}{$p$} \\
\hline & \multicolumn{2}{|c|}{$\begin{array}{l}\text { Ya } \\
\text { Memanfaat } \\
\text { kan }\end{array}$} & \multicolumn{2}{|c|}{$\begin{array}{l}\text { Tidak } \\
\text { Memanfaat } \\
\text { kan }\end{array}$} & \multicolumn{2}{|c|}{ Total } & \\
\hline & $\mathbf{n}$ & $\%$ & $\mathbf{n}$ & $\%$ & $\mathbf{N}$ & $\%$ & \\
\hline $\begin{array}{l}\text { Sikap } \\
\text { Positif }\end{array}$ & 22 & 52,4 & 20 & 47,6 & 42 & 100 & 0,011 \\
\hline $\begin{array}{l}\text { S1kap } \\
\text { Negatif }\end{array}$ & 6 & 20 & 24 & 80,0 & 30 & 100 & \\
\hline Total & 28 & 38,9 & 44 & 61,1 & 72 & 100 & \\
\hline
\end{tabular}

Berdasarkan tabel 8, Responden yang mempunyai sikap positif terhadap pemanfaatan pelayanan kesehatan sebanyak 22 orang atau $(52,4 \%)$, dan yang tidak memanfaatkan sebanyak 20 orang atau $(47,6 \%)$. Sedangkan Responden yang mempunyai sikap 
negatif terhadap pemanfaatan pelayanan

kesehatan sebanyak 6 orang atau (20\%),

dan yang tidak memanfaatkan sebanyak

24 orang atau $(80,0 \%)$.

c. Hubungan Faktor Keyakinan Peserta Jaminan Kesehatan Nasional (JKN) PBI dengan Pemanfaatan Pelayanan Kesehatan di Puskesmas Mandala Mekar Kota Bandung.

Tabel 9 Hubungan Faktor Keyakinan Peserta Jaminan Kesehatan Nasional (JKN) PBI dengan Pemanfaatan Pelayanan Kesehatan di Puskesmas Mandala Mekar Kota Bandung.

\begin{tabular}{|c|c|c|c|c|c|c|c|}
\hline \multirow{3}{*}{ Keyakinan } & \multicolumn{6}{|c|}{ Pemanfaatan } & \multirow{3}{*}{$p$} \\
\hline & \multicolumn{2}{|c|}{ Ya } & \multicolumn{2}{|c|}{ Tidak } & \multicolumn{2}{|c|}{ Total } & \\
\hline & $\mathbf{n}$ & $\%$ & $\mathbf{N}$ & $\%$ & $\mathbf{N}$ & $\%$ & \\
\hline \multicolumn{8}{|l|}{ Tinggi } \\
\hline \multirow{2}{*}{ Rendah } & 24 & 39,3 & 37 & 60,7 & 61 & 100 & 0,852 \\
\hline & 4 & 36,4 & 7 & 63,6 & 11 & 100 & \\
\hline Total & 28 & 38,9 & 44 & 61,1 & 72 & 100 & \\
\hline
\end{tabular}

Berdasarkan Tabel 9, Responden yang memiliki tingkat keyakinan tinggi terhadap pemanfaatan pelayanan kesehatan sebanyak 24 orang atau $(39,3 \%)$, dan yang tidak memanfaatkan sebanyak 37 orang atau $(60,7 \%)$. Sedangkan Responden yang memiliki tingkat keyakinan rendah terhadap pemanfaatan pelayanan kesehatan sebanyak 4 orang $(36,4 \%)$ dan yang tidak memanfaatkan sebanyak 7 orang atau $(63,6 \%)$. d. Hubungan Faktor lokasi Peserta Jaminan Kesehatan Nasional (JKN) PBI dengan Pemanfaatan Pelayanan Kesehatan di Wilayah Kerja Puskesmas Mandala Mekar Kota Bandung.

Tabel 10 Hubungan Faktor lokasi Peserta Jaminan Kesehatan Nasional (JKN) PBI dengan Pemanfaatan Pelayanan Kesehatan di Wilayah Kerja Puskesmas Mandala Mekar Kota Bandung

\begin{tabular}{llllllll}
\hline \multirow{2}{*}{$\begin{array}{l}\text { Lokasi } \\
\text { Sarana }\end{array}$} & \multicolumn{9}{l}{ Pemanfaatan } & \multicolumn{3}{c}{$\boldsymbol{p}$} \\
\cline { 2 - 6 } & Ya & \multicolumn{4}{c}{ Tidak } & \multicolumn{3}{c}{ Total } & \\
\hline Terjangkau & 23 & 39,0 & 36 & 61,0 & 59 & 100 & 1,000 \\
$\begin{array}{l}\text { Tidak } \\
\text { Terjangkau }\end{array}$ & 5 & 38,5 & 8 & 61,5 & 13 & 100 & \\
\hline Total.28 & 28 & 38,9 & 44 & 61,1 & 72 & 100 & \\
\hline
\end{tabular}

Berdasarkan tabel 10, Responden yang mengatakan terjangkau dan memanfaatkan pelayanan kesehatan sebanyak 23 orang atau $(39,0 \%)$, dan terjangkau tetapi tidak memanfaatkan sebanyak 36 orang atau (61,0\%). Sedangkan Responden yang mengatakan tidak terjangkau tetapi memanfaatkan pelayanan kesehatan sebanyak 5 orang atau $(38,5 \%)$. Sedangkan responden yang tidak terjangkau dan tidak memanfaatkan sebanyak 8 orang atau $(61,5$ $\%)$. 
e. Hubungan Faktor Kebutuhan yang dirasakan Peserta Jaminan Kesehatan Nasional (JKN) PBI dengan Pemanfaatan Pelayanan Kesehatan di wilayah kerja Puskesmas Mandala Mekar Kota Bandung.

Tabel 11 Hubungan Faktor Kebutuhan yang dirasakan Peserta Jaminan Kesehatan Nasional (JKN) PBI dengan Pemanfaatan Pelayanan Kesehatan di wilayah kerja Puskesmas Mandala Mekar Kota Bandung.

\begin{tabular}{lllllllll}
\hline \multirow{2}{*}{$\begin{array}{c}\text { Kebutuhan } \\
\text { yang dirasakan }\end{array}$} & \multicolumn{9}{l}{ Pemanfaatan } & \multirow{2}{*}{ Tidak } & \multicolumn{2}{c}{ Total } & \\
\cline { 2 - 7 } & $\mathrm{n}$ & $\%$ & $\mathrm{n}$ & $\%$ & $\mathrm{n}$ & $\%$ & \\
\cline { 2 - 7 } Butuh & 24 & 42,1 & 33 & 57,9 & 57 & 100 & $\mathbf{0 , 4 2 7}$ \\
Tidak & 4 & 26,7 & 11 & 73,3 & 15 & 100 & \\
\hline Total.28 & 17 & 23,6 & 55 & 76,4 & 72 & 100 &
\end{tabular}

Berdasarkan tabel 11, responden yang merasa Butuh terhadap pelayanana kesehatan serta memanfaatkan pelayanan kesehatan sebanyak 24 orang atau $(42,1 \%)$, dan yang tidak memanfaatkan sebanyak 33 orang atau $(57,9 \%)$. Sedangkan Responden yang merasa tidak butuh terhadap pelayanan kesehatan, tetapi memanfaatkan pelayanan kesehatan sebanyak 4 orang atau (26,7\%), dan yang tidak memanfaatkan sebanyak 11 orang atau $(73,3 \%)$.

\section{PEMBAHASAN}

Berdasarkan hasil penelitian yang telah di lakukan di wilayah kerja Puskesmas Mandala Mekar Kota Bandung menunjukkan bahwa yang tidak memanfaatkan pelayanan kesehatana adalah kelompok usia 15-50 tahun dan terdapat hubungan signifikan antara umur dengan pemanfaatan pelayanan kesehatan, dengan ( $p$-value $<0,05)$ yaitu nilai ( $\mathrm{p}$ value $<0,007)$.

Hal ini sejalan dengan penelitian ${ }^{7}$ yang mengatakan ada hubungan signifikan antara variable usia dengan pemanfaatan pelayanan kesehatan, dengan nilai ( $p$ value $<0,0001)$.

Teori Health Service Use yang juga menyebutkan bahwa usia adalah salah satu faktor predisposisi atau internal yang mempengaruhi perilaku seseorang tersebut untuk melakukan pemanfaatan pelayanan kesehatan ${ }^{9}$. Semakin tua seseorang maka daya tahan tubuh seseorang akan semakin menurun dan pada usia lansia derajat penyakit yang dialami akan semakin berat, maka kecenderungan pada usia lansia akan semakin banyak membutuhkan pelayanan kesehatan demi kesembuhan penyakit tersebut $^{8}$ 
1. Hubungan Faktor Sikap Peserta Jaminan Kesehatan Nasional (JKN) PBI dengan pemanfaaatan Pelayanan Kesehatan di Wilayah Kerja Puskesmas Mandala Mekar Kota bandung.

Berdasarkan hasil penelitian, menunjukan bahwa sebanyak 24 orang atau $(80,0 \%)$ responden yang bersikap negatif dan tidak memanfaatkan pelayanan kesehatan. Hasil analisis statistik chi square bahwa nilai p-value pada variabel sikap adalah 0,011 . Hal tersebut menunjukkan bahwa adanya hubungan antara faktor Sikap dengan pemanfaatan pelayanan kesehatan ( $p$ value< 0,05). Penelitian ini sejalan dengan penelitian yang dilakukan oleh burhan $^{10}$ terdapat hubungan yang signifikan antara sikap dengan pemanfaatan pelayanan kesehatan.

Sikap responden pada penelitian menunjukan tindakan atau perilaku yang mengarah kepada pengambilan keputusan dalam berobat. Berdasarkan hasil wawancara terstruktur bahwa mereka yang tidak menggunakan kartu saat berobat, dikarenakan faskes dalam kartu tersebut terdaftar ke puskesmas lain, sedangkan responden bertempat tinggal di wilayah kerja puskesmas mandala mekar. Selain itu responden berasumsi bahwa dengan menggunakan kartu tersebut beliau merasa malu sehingga memilih umum.

2. Hubungan Faktor Keyakinan Peserta Jaminan Kesehatan Nasional (JKN) PBI dengan pemanfaaatan Pelayanan Kesehatan di Wilayah Kerja Puskesmas Mandala Mekar Kota bandung

Berdasarkan hasil penelitian menunjukan bahwa sebanyak 37 orang atau $(60,7 \%) \quad$ yang tidak memanfaatkan pelayanan kesehatan tetapi mempunyai tingkat keyakinan tinggi . Hasil uji statistik diperoleh nilai $(p=0,852)$, artinya tidak ada hubungan antara keyakinan dengan pemanfaatan pelayanan kesehatan di wilayah kerja Puskesmas Mandala Mekar. Hasil penelitian ini sejalan dengan penelitian yang dilakukan oleh Racmawati ${ }^{30}$ dari hasil penelitiannya menunjukkan bahwa Tidak ada hubungan faktor predisposisi (keyakinan) dengan keputusan pasien untuk memanfaatkan pelayanan kesehatan di Puskesmas Tamalanrea Kota Makassar $(\mathrm{p}=0,171)$.

Berdasarakan hasil penelitian bahwa responden kurang kesadaran dalam menjaga kesehatan. Mereka merasa tidak perlu mengakses fasilitas kesehatan apa bila mereka tidak sakit, 
dan mereka tidak berusaha untuk menjaga kesehatannya karena mereka merasa tenang ketika sakit sudah di jaminkan oleh pemerintah, dan yang lebih tidak tenang itu mereka yang bayar sendiri karena jika tidak dibayar akan di non aktifkan. Selain itu ada yang asusmsi bahwa klinik lebih lengkap dan membuatnya lebih nyaman, serta ada yang mengatakan bahwa berdasarkan pengalamannya mereka pernah mendapat pelayanan dari petugas puskesmas yang kurang menyenangkan terkait kesopanan dan keramahan yang diterima, sehingga mereka memilih berobat ke klinik atau peraktek dokter.

Responden yang memilih memanfaatkan kembali pelayanan rawat inap Rumah Sakit Stella Maris Makassar, dengan alasan mereka sudah percaya dengan pelayanan yang diberikan, percaya terhadap kemampuan dokter dan perawat ${ }^{11}$ Dengan menunjukan keramah dan kesopanan, tanggap dan senantiaasa mendengarkan keluh kesah pasien dan menjelaskan dengan baik tentang penyakit yang diderita pasien sehingga pasien akan merasa diperhatikan dan nyaman untuk berobat ${ }^{12}$.

3. Hubungan Faktor Lokasi Peserta Jaminan Kesehatan Nasional (JKN) PBI dengan pemanfaaatan Pelayanan Kesehatan di Wilayah Kerja Puskesmas Mandala Mekar Kota bandung.

Berdasarkan hasil penelitian yang telah di lakukan menunjukan hasil uji statistik diperoleh nilai $(\mathrm{p}=1.000)$. Hal ini berarti tidak ada hubungan antara lokasi dengan pemanfaatan pelayanan kesehatan di wilayah kerja Puskesmas Mandala Mekar.

Hasil analisis menunjukan bahwa lokasi tidak mempunyai hubungan yang bermakna terhadap pelayanan kesehatan di wilayah kerja puskesmas mandala mekar, dalam hal ini disebabkan meskipun karena masih tersedianya kurangnya transfortasi umum menuju puskesmas, bukan suatu masalah karena sebagian besar peserta JKN PBI yang menjadi responden mempunyai kendaraan pribadi menuju puskesmas. Selain itu terdapat transfortasi Ojeg yang bisa digunakan untuk menggantikan angkutan umum.

Hal ini tidak sejalan dengan hasil penelitian $^{13}$ yang mengatakan bahwa 
terdapat hubungan yang bermakna antara akses dengan pemanfaatan pelayanan kesehatan di Puskesmas. Terdapat $79,2 \%$ responden dengan akses layanan yang dekat tidak memanfaatkan puskesmas.

lokasi sarana kesehatan erat kaitannya dengan letak geografis dan akasesbilitas. Akses pelayanan kesehatan adalah pelayanan kesehatan itu harus dapat dicapai oleh masyarakat, tidak terhalang oleh keadaan geografis, sosial, ekonomi, organisasi dan bahasa ${ }^{14}$. Beda halnya dengan penelitian yang dilakukan oleh peneliti bahwa lokasi maupun jarak tidak mempengaruhi responden dalam memanfaatkan pelayanan kesehatan, karena responden pada penelitian ini adalah peserta JKN PBI, yang mana responden tidak bisa beobat dengan menggunakan kartu kepesertaan JKN ke faskes lain. Penggunaan Kartu kepesertaan JKN akan bisa digunakan pada puskesmas yang sesuai dengan faskenya. Jadi mau tidak mau peserta JKN PBI harus berobat ke faskes yang terdaftar $^{3}$ kecuali jika mereka mau menggunakan atau menjadi pasien umum.
4. Hubungan Faktor Kebutuhan yang dirasakan Peserta Jaminan Kesehatan Nasional (JKN) PBI dengan pemanfaaatan Pelayanan Kesehatan di Wilayah Kerja Puskesmas Mandala Mekar Kota Bandung.

Penelitian ini menunjukkan bahwa tidak ada hubungan antara kebutuhan dengan pemanfaatan pelayanan kesehatan dengan nilai (p-value > 0,427). Widartini dan Nopiyanu ${ }^{15}$ mengatakan yang dapat menarik minat pengguna layanan memanfaatkan kembali adalah pelayanan yang memiliki perhatian yang tinggi yaitu kemampuan petugas dalam berkomunikasi serta kemampuan petugas dalam memahami keinginan dan kebutuhan serta dapat mengatasi keluhan pasien.

Hasil penelitian ini berdasarkan wawancara pada responden, apa bila keadaan diri dan keluarganya mengalami sakit maka kebutuhan untuk segera mendapatkan pelayanan kesehatan. Berbeda dengan responden yang berpendapat bahwa menunda kebutuhan untuk mendapatkan pelayanan kesehatan sehingga biasanya berusaha mengobati diri sendiri dengan beli obat warung, obat tradisional atau 
JURNAL SEHAT MASADA VOLUME XIV NOMOR 1 Januari 2020 ISSN : 1979-2344

menuggu sampai parah, baru memamfaatkan pelayanan kesehatan.

\section{SIMPULAN}

1. Gambaran Umum Pemanfaatan Pelayanan Kesehatan

Hasil penelitian ini menunjukan bahwa responden yang memanfaatkan pelayanan kesehatan sebanyak 28 orang atau $(38,9 \%)$ dan yang tidak memanfaatkan 44 orang atau $(61,1 \%)$ dan proposrsi responden terbanyak adalah pada kelompok usia 15-50 tahun, proporsi sikap responden terbanyak yaitu responden dengan Sikap positip sebanyak 41 orang atau $(56,9 \%)$, proporsi keyakinan responden terbanyak yaitu responden yang memilki tingkat keyainan tinggi yaitu sebanyak 61 orang atau $(84,7 \%)$ dan proporsi lokasi responden terbanyak yaitu responden yang lokasinya terjangkau yaitu sebanyak 59 orang atau $(81,9 \%)$ serta proporsi responden yang merasa butuh sebanyak 57 orang atau $(79,2 \%)$.

2. Terdapat Hubungan faktor umur peserta JKN PBI dengan Pemanfaatan Pelayanan kesehatan dengan nilai $p$ value adalah 0,007
3. Terdapat Hubungan faktor Sikap peserta JKN PBI dengan Pemanfaatan Pelayanan kesehatan dengan nilai $p$ value adalah 0,011

4. Tidak ada Hubungan faktor keyakinan peserta JKN PBI dengan Pemanfaatan Pelayanan kesehatan dengan nilai $p$ value adalah 0,852

5. Tidak ada Hubungan faktor Lokasi peserta JKN PBI dengan Pemanfaatan Pelayanan kesehatan dengan nilai $p$ value adalah 1,000

6. Tidak ada Hubungan faktor Kebutuhan peserta JKN PBI dengan Pemanfaatan Pelayanan kesehatan dengan nilai $p$ value adalah 0,427

\section{SARAN}

a. Dinas Kesehatan

Disarankan agar dapat mempertimbangkan kebijakan tentang pemerataan faskes pertama kepesertaan Jaminan Kesehatan Nasional (JKN)

b. Puskesmas

Terkait dengan faktor keyakinan pada penelitian didapatkan bahwa Peserta JKN yang menjadi responden pada penelitian ini kurang kesadaran dalam menjaga kesehatan, mereka merasa tidak perlu mengakses fasilitas 
kesehatan apa bila mereka tidak sakit.

Sehingga Perlu adanya peningkatan

Promosi kesehatan.

c. Peneliti Selanjutnya

Untuk peneliti selanjutnya agar melanjutkan penelitian tentang pemanfaatan pelayanan kesehatan di kota Bandung Khusunya di Puskesmas Mandala Mekar yang dilihat dari faktor eksternal dengan variabel lainnya yang belum ada dalam penelitian ini dan metode yang berbeda untuk menggali lebih dalam, sehingga dapat diketahui yang faktor peserta Jaminana Kesehatan Nasional (JKN) PBI yang berhubungan dengan pemanfaatan pelayanan kesehatan.

\section{DAFTAR PUSTAKA}

1. Undang-Undang Nomor 36 tahun 2009. Tentang Kesehatan- Kementrian Kesehatan. Jakarta.

2. No 40 Tahun 2004 tentang sistem Jaminan Sosial Nasional (SJSN). 3

3. Perpres Nomor 82 tahun 2018. Tentang Jaminan Kesehatan -SIPPU-Setkab. Jakarta

4. Surjayanti, P. (2013). Pemanfaatan Pelayanan Kesehatan Saat anak sakit di dusun. dari

Repository.uksw.edu/bitstream/../T I_462009086-BAB\%2011,Psf.
5. Notoatmodjo, S. (2010) Ilmu Perilaku Kesehatan. Jakarta: Rineka Cipta.

6. Rumengan, dkk (2015) 'Faktor-Faktor yang Berhubungan dengan Pemanfaatan Pelayanan Kesehatan Pada Peserta BPJS Kesehatan di Puskesmas Paniki Bawah Kecamatan Mapanget Kota Manado', Jikmu, 5(1), pp. 88-100

7. Srikandi.W. 2013. Cek Kesehatan anda Pria Usia 50 Tahun. PT elex Media Komputindo Kelompok Gramedia : Jakarta

8. Savitri, D. (2013). Faktor-Faktor yang berhubungan dengan Pemanfaatan Pelayanan Puskesmas Sukmajaya oleh peserta Jamkesmas di kota Depok Provinsi Jawa Barat. Tesis. Fakultas Kesehatan Masyarakat .Universitas Indonesia. dari: Scholer.goegle.ac.id>citations.

9. Notoatmodjo, S. (2010) Ilmu Perilaku Kesehatan. Jakarta: Rineka Cipta.

10.Diktum Kedua dan Keempat Keputusan Menteri Sosial No 146 Tahun 2013

11.M. Fauzi.k. Dkk. (20017) Jurnal Kebijakan Kesehatan Indonesia . dunduh dari https://jurnal.ugm.ac.id/jkki/article/view/2 9001 tanggal 1 Agustus 2019.

12.Lilipory E.R. Faktor yang Mempengaruhi Pemanfaatan Rumah Sakit Di RSUD dr Haulussy Ambon [Skripsi]. Makassar: Universitas Hasanuddin; 2008.

13.Irianti, I. 2018. Faktor Yang Berhubungan Dengan Pemanfaatan Pelayanan Kesehatan Petani Rumput Laut Desa Garassikang Kecamatan Bangkala Barat Kabupaten Jeneponto Tahun 2018. Skripsi. Fakultas Kesehatan Masyarakat. Unuversitas Hasanuddin Makassar. 
14.Agustianai, A. Promosi Kesehatan. 2019. yogyakarta.

15.Rumengan, dkk (2015) 'Faktor-Faktor yang Berhubungan dengan Pemanfaatan Pelayanan Kesehatan Pada Peserta BPJS Kesehatan di Puskesmas Paniki Bawah Kecamatan Mapanget Kota Manado', Jikmu, 5(1), pp. 88-100 